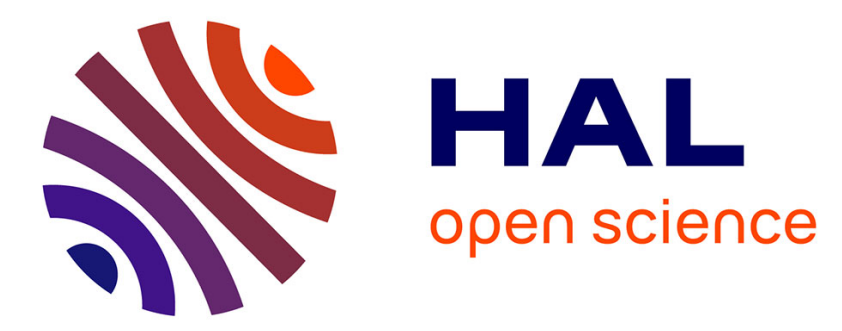

\title{
Dynamic versus static stress triggering and friction parameters: Inferences from the November 23, 1980, Irpinia earthquake
}

Christophe Voisin, Michel Campillo, Ioan R. Ionescu, Fabrice Cotton, Oona Scotti

\section{To cite this version:}

Christophe Voisin, Michel Campillo, Ioan R. Ionescu, Fabrice Cotton, Oona Scotti. Dynamic versus static stress triggering and friction parameters: Inferences from the November 23, 1980, Irpinia earthquake. Journal of Geophysical Research, 2000, 105 (B9), pp.21647-21659. 10.1029/2000JB900147 . hal-00315342

\section{HAL Id: hal-00315342 \\ https://hal.science/hal-00315342}

Submitted on 24 Jan 2021

HAL is a multi-disciplinary open access archive for the deposit and dissemination of scientific research documents, whether they are published or not. The documents may come from teaching and research institutions in France or abroad, or from public or private research centers.
L'archive ouverte pluridisciplinaire $\mathbf{H A L}$, est destinée au dépôt et à la diffusion de documents scientifiques de niveau recherche, publiés ou non, émanant des établissements d'enseignement et de recherche français ou étrangers, des laboratoires publics ou privés. 


\title{
Dynamic versus static stress triggering and friction parameters: Inferences from the November 23, 1980, Irpinia earthquake
}

\author{
C. Voisin and M. Campillo \\ Laboratoire de Géophysique Interne et Tectonophysique, Observatoire de Grenoble \\ Université Joseph Fourier, Grenoble, France
}

I. R. Ionescu

Laboratoire de Mathématiques Appliquées, Université de Savoie, Le Bourget-du-Lac, France

F. Cotton and O. Scotti

Institut de Protection et de Sûreté Nucléaire, Fontenay aux Roses, France

\begin{abstract}
This paper concentrates on the problem of fault interaction and earthquake triggering through the 1980 Irpinia, Italy, sequence. More specifically, this paper deals with the problem of the triggering of the second subevent by the mainshock. The interaction between the two segments is modeled through a dynamic Coulomb failure function. The aims of this paper are, first, to discriminate between the dynamic and the static stress effects on the triggering, if these effects exist, second, to estimate the fault strength relative to the initial state of stress, third, to determine the parameters of a slip-dependent friction law that lead to the observed delay of $20 \mathrm{~s}$. Numerical simulations show that the critical slip $D_{c}$ may range from $0.03 \mathrm{~m}$ up to $1.7 \mathrm{~m}$, and that the initial slope of the friction law $\mu^{\prime}(0)$ must be lower than $0.04 \mathrm{~m}^{-1}$. We show that the relative magnitude of the fault strength and the initial state of stress govern the existence and value of a $D_{c}$ lower threshold under which the fault always ruptures before $13 \mathrm{~s}$. A close to failure fault is not consistent with a critical slip $D_{c}$ less than $0.8 \mathrm{~m}$, whereas small values of $D_{c}$, typically $0.03 \mathrm{~m}$, imply a far from failure fault. General results concern the effect of a dynamic stress pulse. We show that an event can be triggered by a transient stress pulse and that in this case the event can have an initiation duration much longer than the pulse duration. We show that it is possible to explain both the triggering and the time delay only with the effect of the transient stress pulse. This may explain aftershock triggering even in regions of negative Coulomb failure function or long distance triggering of earthquakes by propagating waves.
\end{abstract}

\section{Introduction}

Fault interaction and earthquake triggering have been studied either with dynamic [Harris and Day, 1993; Hill et al., 1993; Bodın and Gomberg, 1994; Gomberg and Bodin, 1994; Gomberg and Davis, 1996; Gomberg et al., 1997,1998] or static stress changes [e.g. Smith and Van de Lindt, 1969; Rybrckı, 1973; Das and Scholz, 1981; Stern and Lisowskr, 1983; Simpson et al., 1988; Okada and Kasahara, 1990; Reasenberg and Simpson, 1992; Harris and Simpson, 1992; Jaumé and Sykes, 1992; Stein et al., 1992, 1994; King et al., 1994; Harris et al.,

Copyright 2000 by the American Geophysical Union.

Paper number 2000JB900147.

0148-0227/00/2000JB900147\$09.00
1995; Harris and Simpson, 1996; Deng and Sykes, 1996; Jaumé and Sykes, 1996; Nostro et al., 1997; Reasenberg and Simpson, 1997; Harris and Simpson, 1998; Hardebeck et al., 1998; Nalbant et al., 1998; Toda et al., 1998; Trozse et al., 1998]. The latter studies use the concept of the static Coulomb failure stress $(\triangle C F S)$ and most clearly demonstrate the correlation between the triggering of earthquakes and the positivity of the $\triangle C F S$. However, it is clear that triggering also occurs in regions where $\triangle C F S \leq 0$, that is, in regions of stress shadows and also far away from the event, where static $\triangle C F S \approx 0$ as observed after the 1992 Landers earthquake [e g., Hzll et al., 1993; Anderson et al., 1994; Boden and Gomberg, 1994]. These studies and observations remind us of some unresolved questions [Harris, 1998]: Do dynamic and/or static stress changes trig- 


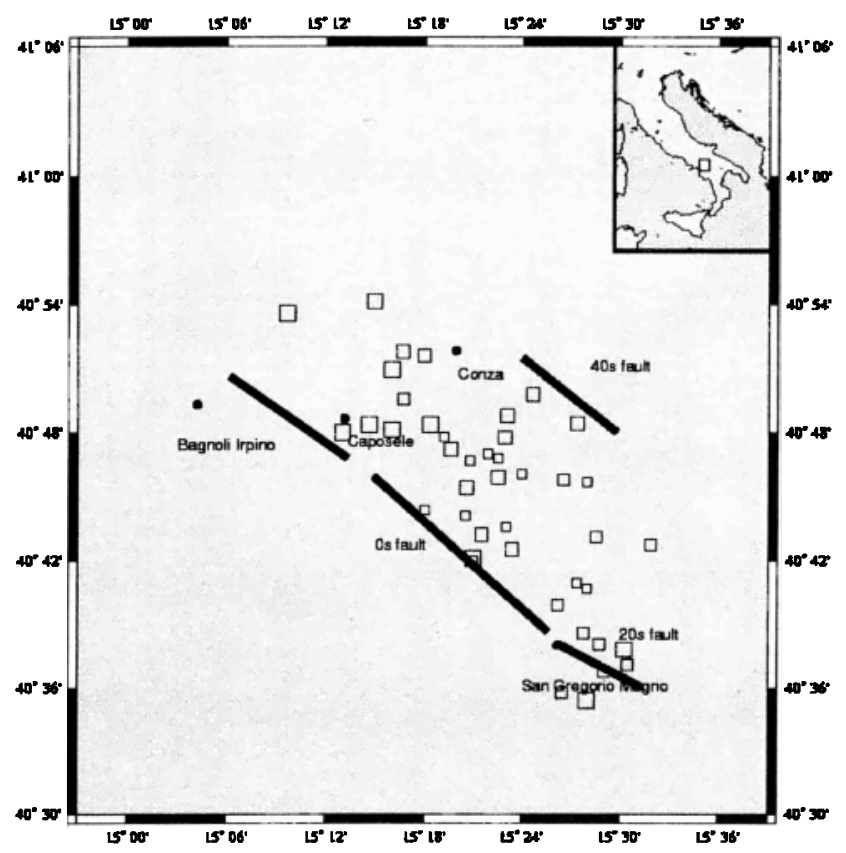

Figure 1. Map of the location of the fault segments of the November 23, 1980 Irpinia (Italy) earthquake sequence (and principal aftershocks). The rupture propagates on the $0 \mathrm{~s}$ fault and jumps to the $20 \mathrm{~s}$ fault segment. Note the strike angle between these two segments: about $10^{\circ}$. After $40 \mathrm{~s}$, the third segment ruptures.

ger earthquakes? Is there a triggering threshold? The 1980 Irpinia earthquake offers the opportunity to answer these questions and to constrain the mechanics of earthquake triggering. First, the use of geologic observations [Pantosti et al., 1993], geodetic data [Pingue et al., 1993] and strong motion accelerograms [Vaccar et al., 1993; Cocco and Pacor, 1993] provided a good knowledge of the history of the Irpinia rupture. This event can be decomposed into three subevents (see Figure 1 for the location of the fault segments). The first one is the mainshock, associated with a normal slip of $1.5 \mathrm{~m}$ and a seismic moment of $10^{19} \mathrm{~N} \mathrm{~m}$. The second shock called the $20 \mathrm{~s}$ event has a seismic moment of $4.10^{18} \mathrm{~N} \mathrm{~m}$, estimated from seismological data [Cocco and Pacor, 1993]. The last event, called the 40s event has a seismic moment of $3.10^{18} \mathrm{~N} \mathrm{~m}$. Second, the stress field produced by the mainshock has been modeled by Belardinell et al. [1999] in terms of a dynamic Coulomb failure function. A transient stress peak of 0.6 MPa reach the second fault segment and is followed by the static stress field. Third, we have developped a numerical procedure that is able to model the interaction between the fault segments. This procedure is based o:l a finite difference method that allows the computation of a time delay of the order of 20 s without encountering numerical instabilities.

Since the second event did occur, the main problem we focus on is whether the dynamic pulse or the static stress variation triggered the second subevent. The dy- namic triggering theory stumbles over the problem of the time delay between the wave passage and the triggering of the event. Actually, the first question is to know why did a dynamic stress peak of $0.6 \mathrm{MPa}$ not trigger the event before the static stress was reached. The two (first and second) subevents are separated in time by nearly $20 \mathrm{~s}$. Belardinelli et al. [1999] computed the dynamic stress caused by the rupture of the first subevent. The origin of time $t_{0}$ chosen by these authors and used in this study is the onset of the rupture on the first subevent. These modeling results of Belardinelli et al. [1999] show that the dynamic stress peak on the second subevent fault plane is reached at time $t \approx 8 \mathrm{~s}$ after $t_{0}$. The static stress level on the second event is reached nearly $14 \mathrm{~s}$ after $t_{0}$. In other words, the time between the arrival of the stress perturbation on the second fault and the onset of the rupture of the second segment is about $18 \mathrm{~s}$, assuming $2 \mathrm{~s}$ for the wave propagation between the two faults. The duration of the transient dynamic stress perturbation on the second fault is about $12 \mathrm{~s}$. The time between the static stress being reached and the onset of the rupture on the second segment is approximately $6 \mathrm{~s}$. In this study, the details of the loading history of the second fault segment are taken into account in the initiation process simulation and analysis. The initiation duration is then the duration between the beginning of the stress perturbation and the onset of the rupture on the second fault segment. This initiation duration is then equal to $18 \mathrm{~s}$.

The rupture initiation stage has been described in papers about laboratory experiments [e.g., Ohnaka, 1996]: this is a slip-weakening period of time during which the slip velocity increases slowly, followed by the propagation stage. Campillo and Ionescu [1997] theoretically studied the initiation phase in the case of a slip weakening friction. They show how the initiation duration is linked to the friction law parameters in the case of an infinite and homogeneous fault. Furthermore, Dascalu et al. [2000] proposed a similar analysis for a finite fault. Our working hypothesis is to relate the time delay of $18 \mathrm{~s}$ with the initiation duration, assuming a slip-weakening friction. We attempt to answer to a set of questions,

1.Is it possible to discriminate between the dynamic and the static effects on the triggering of the second subevent, if these effects exist?

2.Is it possible to estimate the fault strength relatively to the initial state of stress?

3. Does the timing of rupture with respect to the loading constrain the friction law parameters?

In other words, we want to determine the domain $\mathcal{D}$ which contains the suitable values of the friction law parameters that lead to an initiation duration of $18 \mathrm{~s}$, estimate the fault strength and discuss the question of the dynamic triggering of earthquakes. To achieve these three goals, we perform a series of computations, varying the friction law parameters $D_{c}$ (critical slip) and $\mu^{\prime}(0)$ (slope of the friction at the origin) with or without 


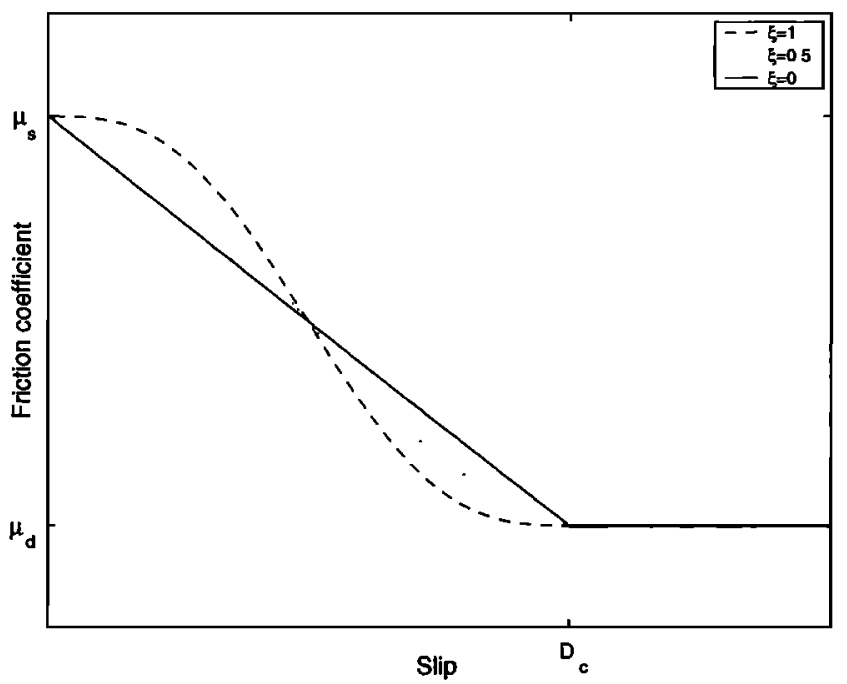

Figure 2. The slip-dependent friction law used in our computations. $D_{c}$ is the critical slip as defined by Ohnaka [1996]. The static $\left(\mu_{s}\right)$ and the dynamic $\left(\mu_{d}\right)$ friction cofficients are kept as constants. The parameter $\xi$ modulates the linear friction law with a sine function; $\mu^{\prime}(0)$ is maximum when $\xi=0$ (linear law) and minimum when $\xi=1$ (sine law).

the static stress field, and with different assumptions on the strength of the fault segment.

\section{Description of the Model}

\subsection{Medium}

We consider the two-dimensional (2-D) antiplane elastic problem of slip instability, with two semi-infinite elastic half-spaces bounded by their common side along which a fault of finite length is defined: the second fault. segment. We use a finite difference method to approach the problem of the development of an instability on the fault surface. This method is fully described by Ionescu and Campillo [1999]. The medium is discretized with a grid step of $\Delta x=\Delta y=100 \mathrm{~m}$. The fault length is set to $10 \mathrm{~km}$ [Pantosti et al., 1993], while the entire model has a length of $80 \mathrm{~km}$. The shear wave velocity is fixed to $3000 \mathrm{~m} / \mathrm{s}$, the density of the medium to $2700 \mathrm{~kg} / \mathrm{m}^{3}$, an average value for crustal rocks. The normal stress $S_{N}$ is computed at a depth of $8000 \mathrm{~m}$ : $S_{N}=\rho g z=9.81 * 2700 * 8000=212 \mathrm{MPa}$. This is the depth of the beginning of the rupture front on the second fault segment, as seen by Belardinelli et al. [1999].

\subsection{Friction Law}

We use a slip-dependent friction law derived from the experimental works performed by Ohnaka [1996]. These experiments clearly show the slip dependence of the friction, at least at the beginning of the evolution. Other friction laws, based on rate and state model [Dieterich, 1979; Ruina, 1983], are not so different from the slipdepenclent friction law, since they are regularized with the help of a characteristic slip. The slip-dependent fric- tion law is then the simplest law that describes the beginning of the evolution, the so-called initiation phase. The friction law is fully described by $\tau_{s}, \tau_{d}, D_{c}$ and $\xi$. Figure 2 shows these parameters and their relations. Variables $\tau_{s}$ and $\tau_{d}$ represent the static friction and the dynamic friction, respectively. They are related to the normal stress $S_{N}$ by

$$
\begin{aligned}
\tau_{s} & =\mu_{s} S_{N}, \\
\tau_{d} & =\mu_{d} S_{N},
\end{aligned}
$$

where $\mu_{s}$ and $\mu_{d}$ are the static and the dynamic friction coefficients. We fix $\mu_{s}$ to be 0.6 [Byerlee, 1978 Zoback and Healy, 1984; Iio, 1997], and $\mu_{d}$ to 0.56, so that the stress drop is about $8.3 \mathrm{MPa}$, a typical value
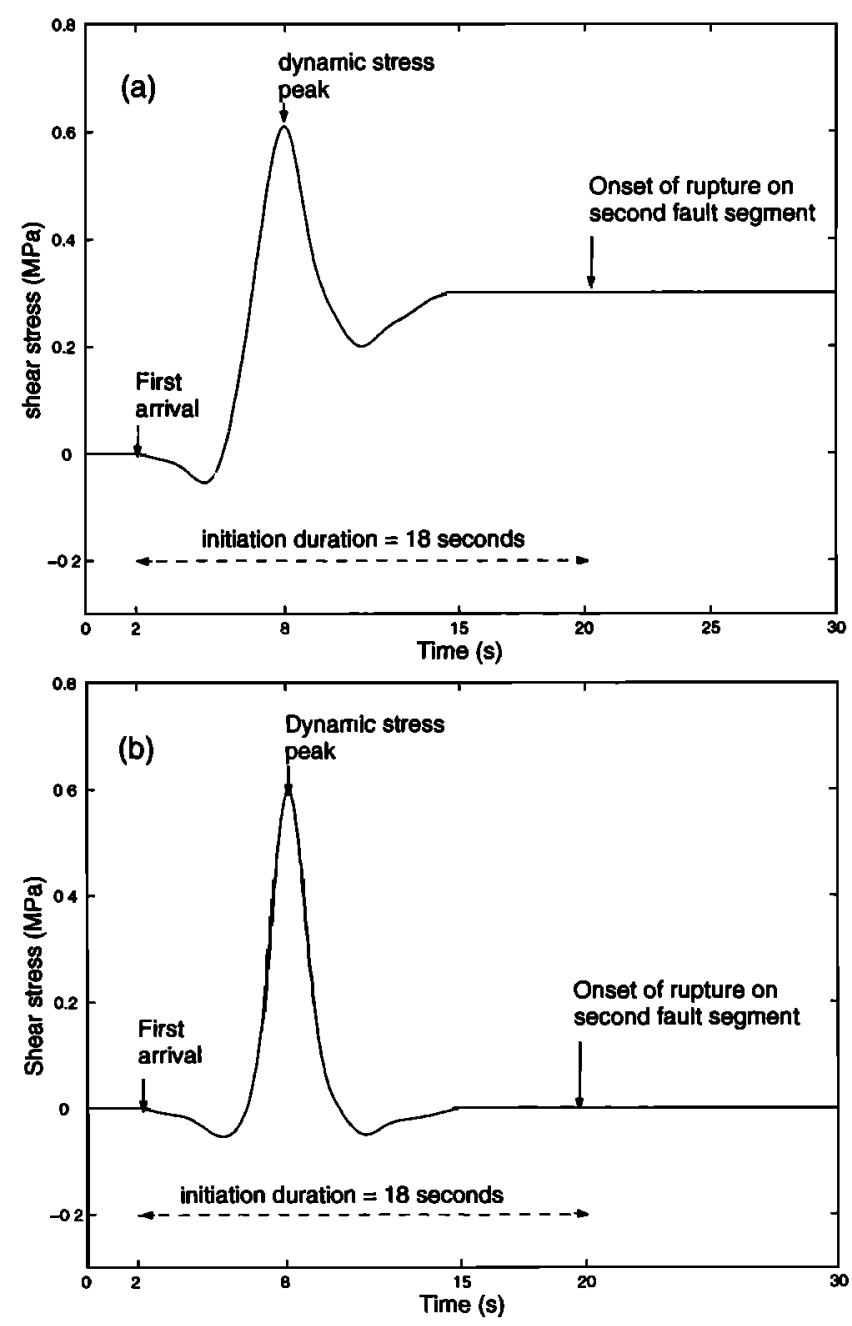

Figure 3. The wave shape used in this study. (a) The complete C.FF computed by Belardinell et al. [1999]. (b) The dynamic pulse alone, with a static stress field of $0 \mathrm{MPa}$. The origin of time corresponds to the onset of the rupture on the first segment. The maximum of the shear stress occurs at time $t \approx 8 \mathrm{~s}$. The static stress field is reached at time $t \approx 15 \mathrm{~s}$. The onset of the rupture on the second fault segment is recorded at $t=20$ s. Assuming $2 \mathrm{~s}$ of propagation, we then consider an initiation duration of $18 \mathrm{~s}$. 
for intraplate earthquakes. $D_{c}$ is the critical slip: it represents the necessary amount of slip for the fault to weaken completely. Parameter $\xi$ modulates the linear friction law with a sine function [Ionescu and Campillo, 1999]. This parameter ranges from 0 (linear friction) to 1 (sine friction). The slope of the friction law at the origin $\mu^{\prime}(0)$ is related to $D_{c}$ by

$$
\mu^{\prime}(0)=\frac{(1-\xi)}{D_{c}}\left(\mu_{s}-\mu_{d}\right)
$$

Ionescu and Campillo [1999] demonstrate the link between $\mu^{\prime}(0)$ and the initiation duration: the lower $\mu^{\prime}(0)$ is, the longer the duration is. The extreme case $\mu^{\prime}(0)=$ $0(\xi=1)$ leads to a stable equilibrium position, when no instability can develop on the fault. We concentrate on cases $\mu^{\prime} \leq \Delta \mu / D_{c}(\xi \geq 0)$. The cases $\mu^{\prime} \geq \Delta \mu / D_{c}$ $(\xi \leq 0)$ are not discussed here, but since $\mu^{\prime}(0)$ is then greater, one can expect a duration of initiation shorter than for a linear friction law, that is, an almost instantaneous rupture. Consequently, we consider the linear friction law as a limit to our study.

\subsection{Incident Stress Waveform}

We consider that the interaction between the first and the second segment is done through the propagation of the waves and the static elastic response of the medium. Figure 3 presents the dynamic Coulomb failure function computed by Belardınelli et al [1999]. The origin of time is the onset of the rupture of the first segment. The first wave arrives on the second fault segment at time $t=$ $2 \mathrm{~s}$. The dynamic stress peak is reached at time $t=8$ $\mathrm{s}$. The last wave arrives at time $\mathrm{t}=15 \mathrm{~s}$. This lapse in time, from $2 \mathrm{~s}$ to $15 \mathrm{~s}$ is referred to as the dynamic stage. After time $\mathrm{t}=15 \mathrm{~s}$, the shear stress does not evolve anymore on the second fault segment: the static configuration is reached. The onset of the rupture of the second fault segment is recorded at time $t=20$ s. The dynamic stage is a transient stage that leads to the static stress configuration [Cotton and Coutant, 1997]. In accordance to the actual geometry of the Irpunia fault system, we consider a plane wave with an angle of incidence of $80^{\circ}$ (Figure 4). One of our goals is to cliscriminate between the dynamic and the static effects on the triggering of earthquakes. To achieve this goal, we separate the CFF in a dynamic part (from $0 \mathrm{~s}$ to $15 \mathrm{~s}$ ) and a static part (from $15 \mathrm{~s}$ to $\infty$ ). Figure $3 \mathrm{a}$ presents the dynamic CFF computed by Belardinelli et al. [1999] and used in section 5 of this paper. Figure $3 \mathrm{~b}$ presents the shape of the dynamic pulse used in section 4. The shape of this pulse is the one of the CFF, except that the signal comes back to zero at time $t=15 \mathrm{~s}$. In other words, we consider the static stress field to be zero in this case. As the normal stress dynamic variation on the second fault segment is small (less than $0.1 \mathrm{MPa}$ ) compared to the shear stress one (more than 0.6 MPa) [Belardınelli et al., 1999], we neglect the normal stress variation effect. We assimilate the CFF computed by

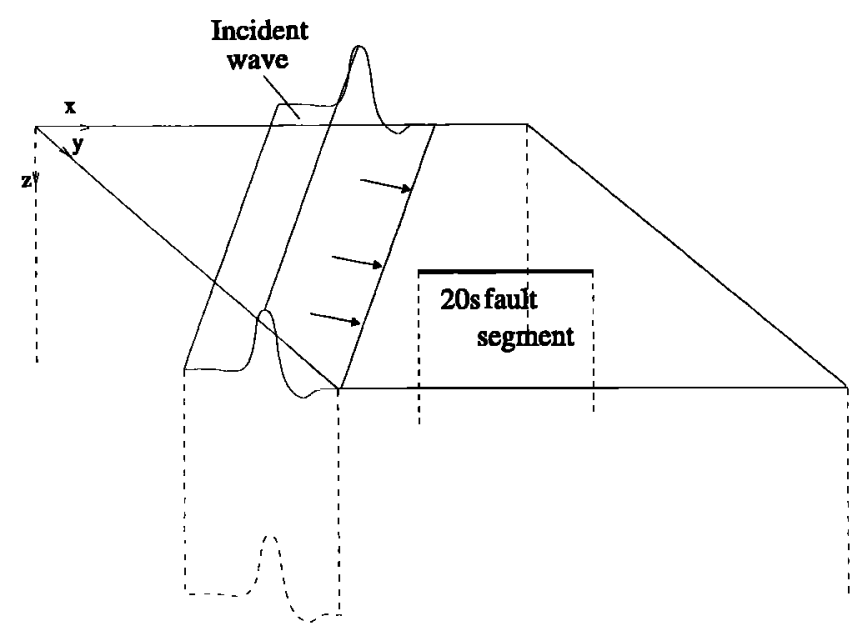

Figure 4. Schematic geometry of the problem (scales are not respected). We use a $2 \mathrm{D}$ antiplane geometry to investigate the triggering of the $20 \mathrm{~s}$ fault segment by the incident plane wave emitted by the first fault segment. This plane wave has an angle of incidence of $80^{\circ}$, since the two fault segments are approximately oriented $\mathrm{N} 315^{\circ}$ and $\mathrm{N} 305^{\circ}$.

Belardinelli et al. [1999] as the incident shear stress $\tau_{z x}$ on the second fault segment.

\section{Examples of Evolution of the System}

Depending on the assumptions about the strength, the loading on the second fault segment, the initial state of stress, and the friction law parameters, the system may behave in three different ways: the first one is referred to as the fast-triggering case and happens when the second fault triggers before $20 \mathrm{~s}$. The second one is the slow-triggering case and happens when the second fault triggers after $20 \mathrm{~s}$. The last case is referred to as the non triggering case and happens when the instaljility a.borts and the second fault remains stable. Figures 5, 6, and 7 present examples of computations done with the complete CFF. The critical slip is 0.9 $\mathrm{m}$, and the fault strength equals the initial state of stress. The only varying parameter is $\mu^{\prime}(0)$ (through thic value of $\xi$ ). These figures illustrate the three possible behaviors of the fault. Figures 5 and 6 show the time evolution of the stress on the second fault segment and in the medium, for a fast-triggering case and for a slow-triggering case. The only difference is $\mu^{\prime}(0), 0.03$ $\mathrm{m}^{-1}$ in the fast triggering case and $0.01 \mathrm{~m}^{-1}$ in the oller case. The two figures are plotted with the same axes. The length and the width of the domain represented is $40 \mathrm{~km}$. The shear stress is plotted on the vertical axis, ranging from 115 to $145 \mathrm{MPa}$. One can see that the behaviors are not fundamentally different from each other, except for the duration of the initiation phase. The stress is decreasing inside the fault segment whereas it is increasing outside. The two stress peaks at each tip of the fault correspond to $1 / \sqrt{r}$ singularities 


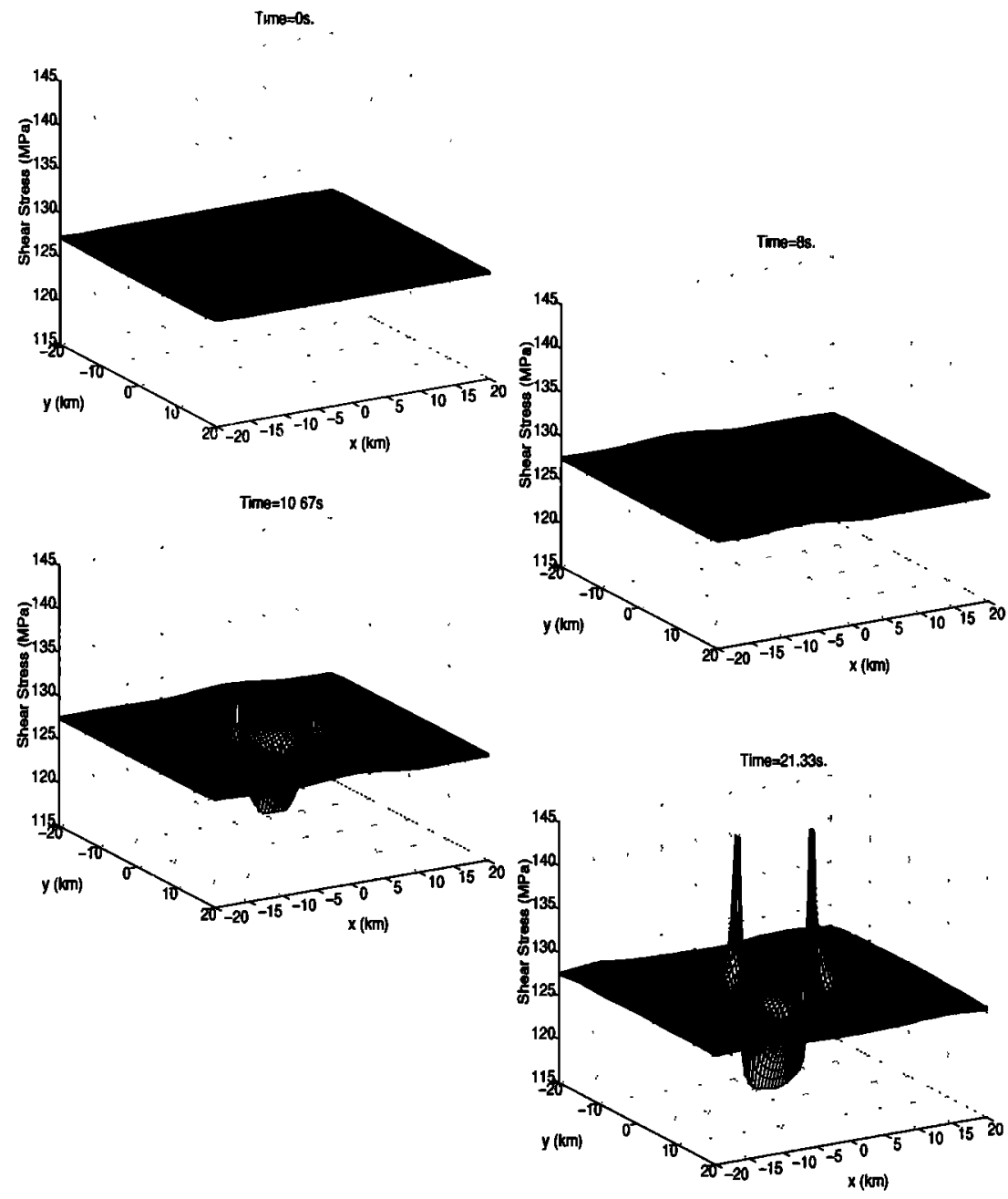

Figure 5. Map view of the shear stress time evolution of the stress in a fast-triggering case. The shear stress falls from $\tau_{s}$ down to $\tau_{d}$ inside the fault segment. At each tip of the fault, the stress decreases as the square root of the distance to the tip. $\mu^{\prime}(0)=0.03 \mathrm{~m}^{-1}, D_{c}=0.9 \mathrm{~m}$. The corresponding length of the initiation zone is $l_{c}=6 \mathrm{~km}$. The length of the fault is $10 \mathrm{~km}$. Then, the ratio $l_{c} / l_{f}<<1$ and the initiation duration is short: the onset of the rupture is around $\mathrm{t}=9$ s.

[Akı and Ruchards, 1980]. In the fast-triggering case the initiation phase lasts 8 to $10 \mathrm{~s}$. In the slow-triggering case, the initiation cluration is much longer than $20 \mathrm{~s}$. Figure 7 presents the third and last case, referred to as the non triggering case, that happens when there is no development of a dynamic instability. The difference with the previous case is $\mu^{\prime}(0)$, that is now $0.005 \mathrm{~m}^{-1}$. The stress evolution is limited: one can observe small stress peaks at each tip of the fault. Inside the fault segment the stress release is very limited and non homogeneous, due to the wave reflection at each end of the fault. For such $\mu^{\prime}(0)$ the unstable evolution of the fault is so slow that the negative pulse of the incident wave stops it. Ionescu and Campillo [1999] have investigated the effect of $\mu^{\prime}(0)$ on the initiation duration, in the framework of the perturbation theory. They have shown that the initiation duration is linked to the ratio between the theoretical length of the initiation patch $l_{c}$ and the fault length $l_{f}$. When $l_{c} / l_{f}<<1$, the initia- tion duration is small. When $l_{c} / l_{f} \approx 1$, the initiation duration is longer. When $l_{c} / l_{f}>>1$, the fault is stable and the initiation duration is infinite. The rupture is not observed. Ionescu and Campillo [1999] relates $\mu^{\prime}(0)$ to $l_{c}$ (equation (24) in their paper) by

$$
l_{c}=\frac{\pi G}{2 S_{N} \mu^{\prime}(0)}
$$

Since the length of the initiation patch is related to $\mu^{\prime}(0)$, the lower $\mu^{\prime}(0)$ is, the longer the duration of the initiation phase is. Equation (4) defines $l_{c}$ in the case of an infinite fault. In our simulations the fault has a finte length of $10 \mathrm{~km}$. However, if we calculate $l_{c}$, the theoretical length of the initiation zone, for the three cases previously described, we obtain $l_{c}=6 \mathrm{~km}$ for the fast-triggering case, $18 \mathrm{~km}$ for the slow-triggering case and $36 \mathrm{~km}$ for the non triggering case. These three theoretical lengths are to be compared with the fault length: $10 \mathrm{~km}$. When $l_{c}$ is lower than the fault length, 

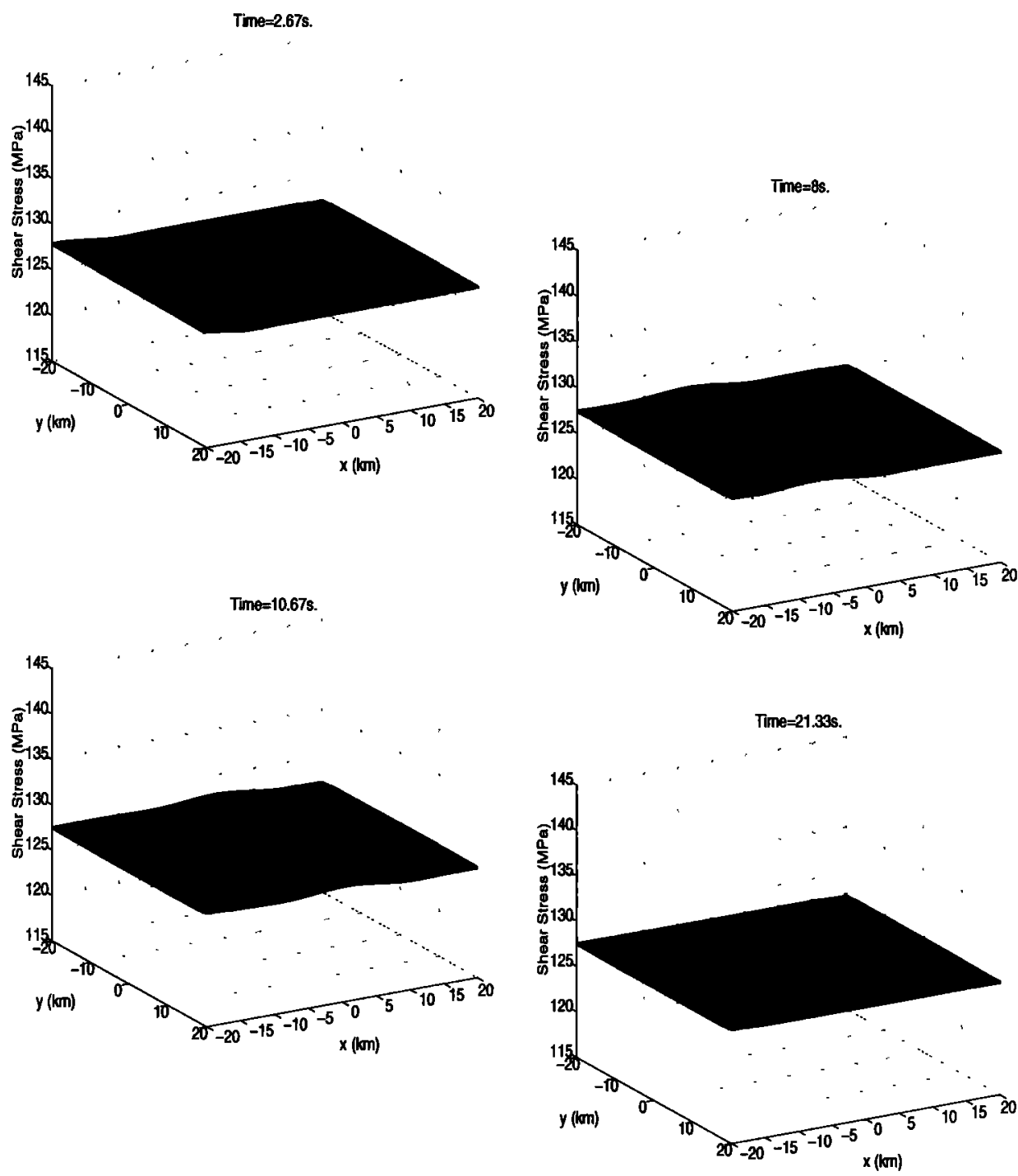

Figure 6. Map view of the shear stress time cvolution of the stress in a slow-triggering case. Actually, the different stages shown here are the same as in figure 5. The difference lies in the time evolution, much slower in this case. The last stage ( $t=21.33 \mathrm{~s})$ of the slow-triggering case looks very similar to the second stage of the fast-triggering case $(t=8 \mathrm{~s})$. The initial slope of friction is $\mu^{\prime}(0)=0.01 \mathrm{~m}^{-1}$, and the critical slip is $D_{c}=0.9 \mathrm{~m}$. The corresponding length of the initiation zone is $l_{c}=18 \mathrm{~km}$. The ratio $l_{c} / l_{f}>1$ and consequently, the initiation duration is far more longer than in the fast-triggering case.

the triggering is easy. This is the fast-triggering case When $l_{c}$ is of the same order than the fault length, the inltiation duration is much longer. This is the slowtriggering case. When $l_{c}$ is much greater than the fault length, the initiation process is not possible: this is the non triggering case [Dascalu et al., 2000]. The friction parameters govern the fault evolution. The transition from one case to the other is continuous, which allows us to determine a set of friction parameters relevant to our problem.

\section{Numerical Study Without the Static Stress Field}

Our aim in this section is to show that an event can be triggered by a transient stress pulse and that, in this (asce, lile muliation duration can be much longer than ila pulse duration.

\subsection{Casc: of a "Close to Failure" Fault Segment}

Wo asmume lhat the shear strength equals the init.lal state of stress, in such a way that any perturbation Icacls to all imslable evolution of the fault. The fault segment. is 113 an cquilibrium position, exactly on the verge to slip. ligure 8 shows the results of our compulations. Tho reritical slip $D_{c}$ is plotted on the $\mathrm{x}$ axis versus the initial slope of the friction law $\mu^{\prime}(0)$. All symbols correspond to the fast-triggering cases, except the squares that correspond indifferently to slow-triggering or non triggering cases. The fast-triggering cases are sorted by initiation duration. The relevant cases are the 15-20 s cases. Some of them are shown by big as- 
terisks in Figure 8. However, since the initiation duration is a continuous function of $\mu^{\prime}(0)$, no doubt that we could find relevant cases for $D_{c}$ between $0.8 \mathrm{~m}$ up to $1.5 \mathrm{~m}$. These cases are not apparent because of the discreteness of the calculations but are shown by the thick dashed line. Relevant cases correspond to $D_{c}$ values lower than $1.5 \mathrm{~m}$, and ranging from 0.015 to 0.025 $\mathrm{m}^{-1}$ for $\mu^{\prime}(0)$. Values of $\mu^{\prime}(0)$ smaller than $0.015 \mathrm{~m}^{-1}$ lead to the third case referred to as the non triggering case. For such $\mu^{\prime}(0)$, the unstable evolution of the fault is so slow that the negative pulse of the incident wave stops it. We assume a complete restoration of the friction when a point stops sliding [Scholz, 1990]: it means that each stopped point has to be reloaded to $\tau_{s}$ to start sliding again. As soon as the sliding at some points on the fault is stopped, the actual length of the slipping patch is reduced. The unstable evolution of the fault is made more difficult, in some cases impossible. Finally, the shear stress on the fault has been partially released to a value between $\tau_{s}$ and $\tau_{d}$. The evolution of the whole fault is the result of two competing effects: the positive pulse that loads the fault and produces the instability, and the negative pulse that unloads it and may lead to a complete arrest of the process (Figure 7). Since we deal with a nonlinear problem, it is not trivial to find any relation between the triggering and the friction law that prescribes the evolution of the system. The initiation process will continue if the dynamic effects dominate over the unloading of the fault by the stress wave. If not, the evolution is stopped before the propagation phase is reached. Small values of $D_{c}$ (lower than $0.8 \mathrm{~m}$ ) always lead to short initiation duration (less than $13 \mathrm{~s}$ ), whatever the value of $\mu^{\prime}(0)$. For such values of $D_{c}$ the fault is sufficiently loaded by the stress pulse
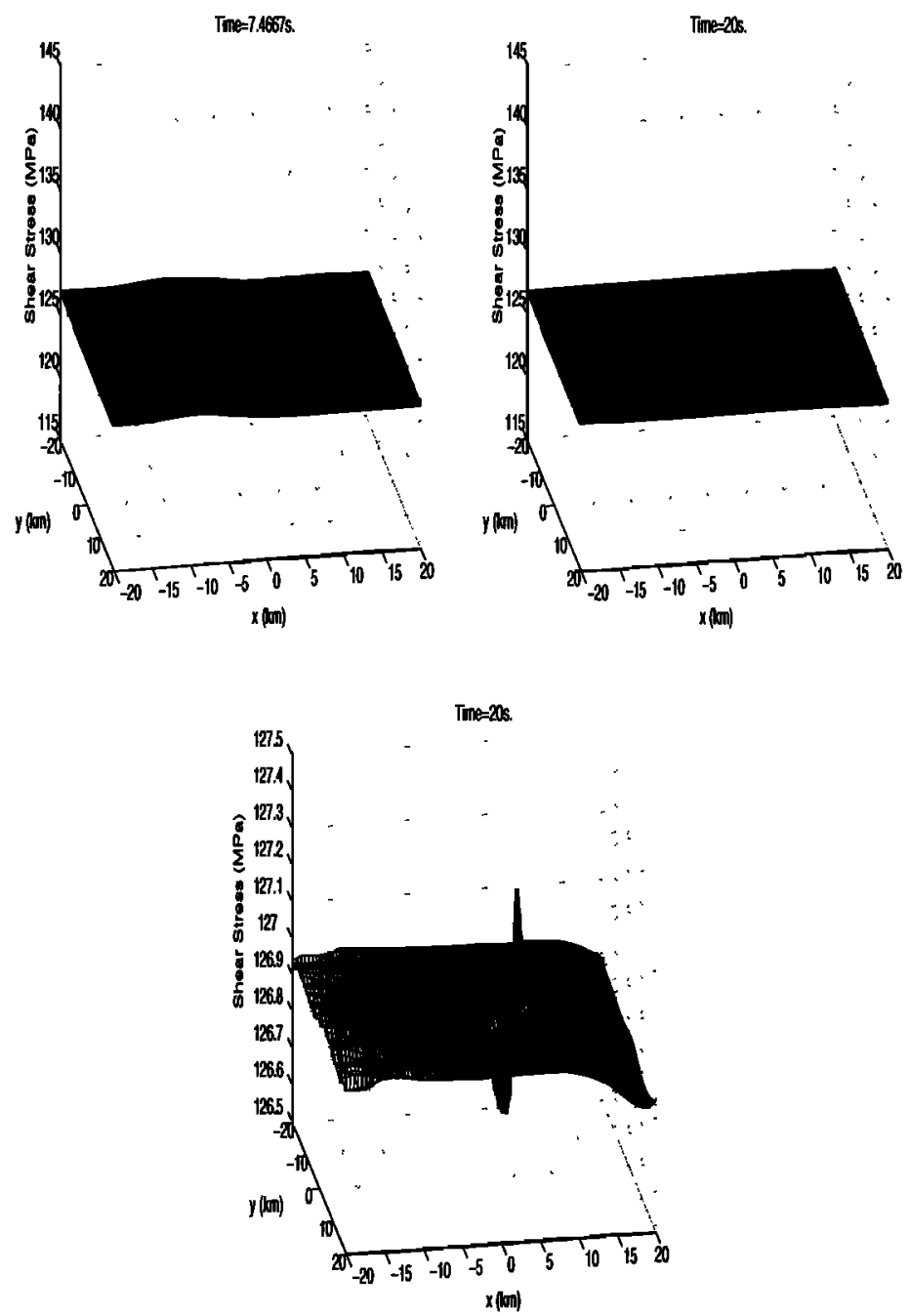

Figure 7. Map view of the time evolution of the shear stress in a nontriggering case. The two first snapshots $(t \approx 7 \mathrm{~s}$ and $\mathrm{t}=20 \mathrm{~s}$ ) have the same vertical axis values for the comparison with the previous cases. The third snapshot is a zoom of the second one. Once again, the tips of the fault exhıbit small stress concentrations. The main difference lies in the stress release inside the fault, inhomogeneous $1 \mathrm{n}$ this case. The initial slope of friction is $\mu^{\prime}(0)=0.005 \mathrm{~m}^{-1}$, the critical slip is $D_{c}=0.9 \mathrm{~m}$. The corresponding length of the initiation zone is $l_{c}=36 \mathrm{~km}$. The ratio $l_{c} / l_{f}>>1$, and consequently, the initiation process is stopped. The rupture (propagation) stage will never be attained. 


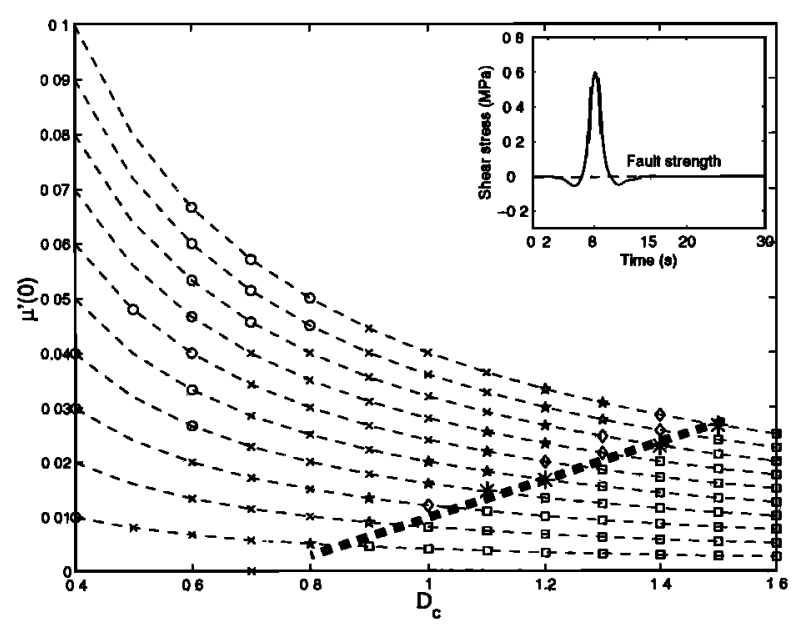

Figure 8. Time before rupture for a close to failure fault segment. The snapshot shows the configuration used for these simulations : we consider only the dynamic stress pulse. The fault strength equals the initial state of stress. The results are sorted by range of duration of initiation ( 7 to $9 \mathrm{~s}$ : circles; 9 to $11 \mathrm{~s}$ : crosses; 11 to $13 \mathrm{~s}$ : stars; 13 to $15 \mathrm{~s}$ : diamonds; 15 to $20 \mathrm{~s}$ : big asterisks; monevent: squares). The label nonevent corresponds to the second and third cases described in section 3 The dashed lines correspond to theoretical relations between $\mu^{\prime}$ and $D_{c}$ for $\xi$ varying from 0.0 to 0.9 . The thick dashed line describes the domain $\mathcal{D}$ : the complying values range from $0.8 \mathrm{~m}$ to $1.6 \mathrm{~m}$ for $D_{c}$ with $\mu^{\prime}(0)$ lower than $0.038 \mathrm{~m}^{-1}$.

to rupture regardless of the initial shape of the friction law. This particular value of $D_{c}$ constitutes a minimum critical slip threshold that must be exceeded to match the observed initiation duration.

\subsection{Case of a "Far From Failure" Fault Segment}

'The provious section was supported by the idea of a close to failure fault, which can be related to the liypothesis of a critical state of stress for the upper crust. [ค.g., Bak and T'ang, 1989; Grasso and Sornette, 1998]. In this section we explore the possible behaviors of a fault segment for which the initial stress is lower than the strength (see the snapshot in Figure 9). In this particular case, the shear strength is set $0.3 \mathrm{MPa}$ above the initial statc of stress. The incident stress wave is the same as in the previous section. The results ar shown on Figure 9, on which we plot $D_{c}$ versus $\mu^{\prime}(0)$ The comparison with Figure 8 shows that there is now a larger range of $\left(D_{c}, \mu^{\prime}\right)$ couples leading to a nontriggering case (see section 3 ) and therefore not relevant for our study. A careful look at Figure 9 indicates that small values of $D_{c}(0.6 \mathrm{~m})$ can lead to long duration of initiation. When the critical slip is lower than $0.4 \mathrm{~m}$, the fault segment always turns to a fast-triggering case, independently from the initial shape of the friction law. This implies that the time evolution of the finite fault segment is more sensitive to $\mu^{\prime}(0)$, rather than to $D_{c}$.
The values of $\mu^{\prime}(0)$ complying with the observed delay are lower than $0.038 \mathrm{~m}^{-1}$, whereas $D_{c}$ ranges from 0.5 m to $1.2 \mathrm{~m}$. They are shown by the thick dashed line in Figure 9.

\section{Numerical Study With the Complete CFF}

The aim of the previous sections was to demonstrate that it is possible to explain a $20 \mathrm{~s}$ delay before the rupture really occurs only by considering the effect of a transient stress pulse. This was done without taking into account the static stress field. The CFF computed by Belardinelli et al. [1999] shows that the static stress is reached after $15 \mathrm{~s}$. We have already seen that the shear strength on the fault is not well constrained by the value of the observed delay, since it is possible to reach long initiation duration in both cases of far or close to fallure fault. The question is now to know what are the implications of the static stress field component on the duration of the initiation phase and if it is possible to constrain the fault strength relatively to the static stress field using the delay duration.

\subsection{Computations for a Close to Failure Fault}

In this section, the fault strength is set to the initial state of stress, that is the fault is on the verge to slip. Figure 10 summarizes all the computations carried out under these particular conditions. The comparison between Figures 8 and 10 highlights the role played by the static stress, since it is the only difference between l.hese two setis of simulations. There is no fundamental diflerence between these two figures. The threshold for I. Ic $D_{c}$ values is $0.8 \mathrm{~m}$, the same as in figure 8 : under $0.8 \mathrm{~m}$, the serond fault segment always ruptures before I:3 F Pigur I 10 shows that even in this configuration

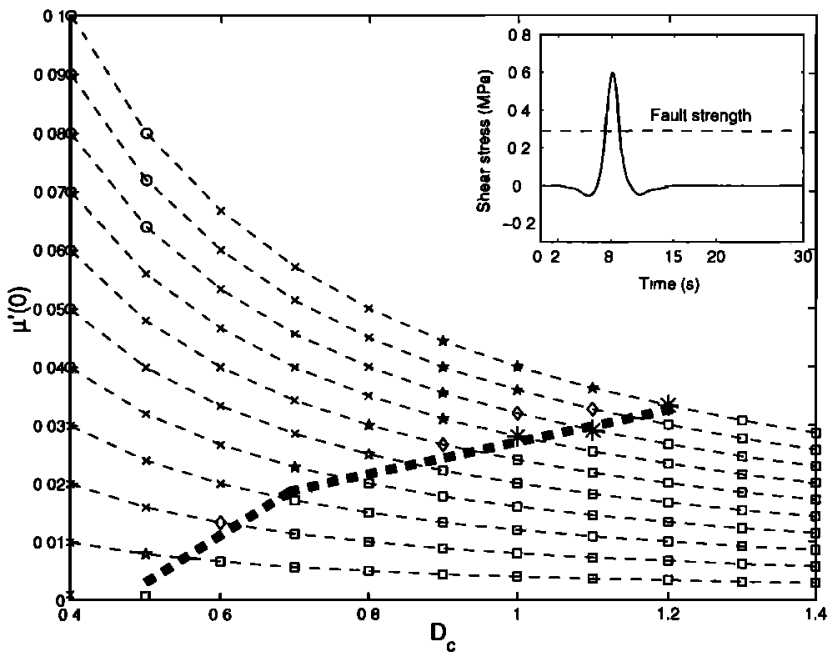

Figure 9. Same legend as in Figure 8 . We use only the dynamic stress pulse. The fault strength is greater than the initial state of stress. The thick dashed line show the values of $D_{c}$ and $\mu^{\prime}(0)$ that fit with the observed clelay of approximately $18 \mathrm{~s}$. 


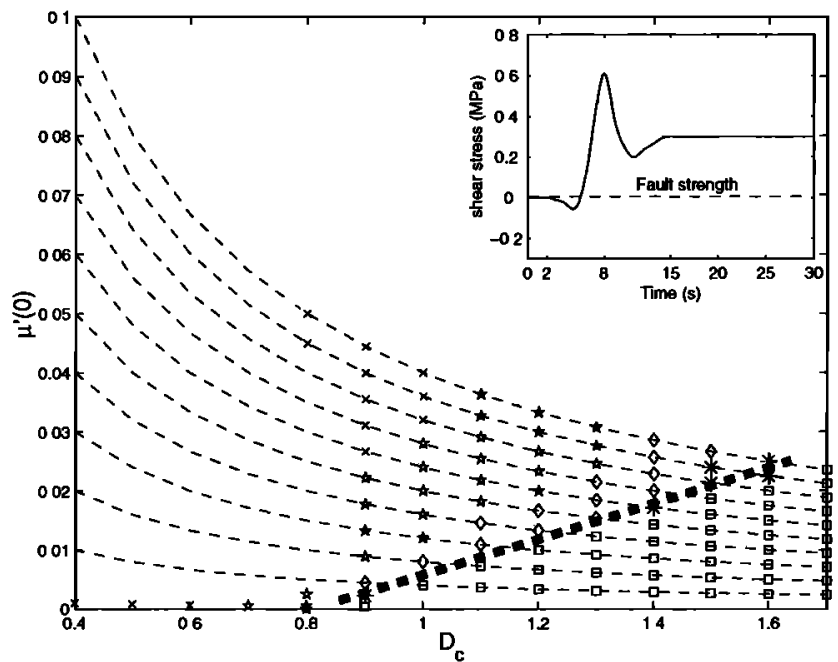

Figure 10. Same legend as Figure 8 . We use the complete CFF computed by Belardinelli et al. [1999]. The fault strength equals the initial state of stress. The thick dashed line shows the complying values of the critical slip $D_{c}$ and of $\mu^{\prime}(0)$. The domain $\mathcal{D}$ extends from 0.8 nn to $1.7 \mathrm{~m}$ for $D_{c}$, with $\mu^{\prime}(0)$ lower than $0.038 \mathrm{~m}^{-1}$.

of a close to failure fault, highly favourable to the rupture, it is possible to find long initiation duration: the domain $\mathcal{D}$ is now extended from 0.8 to $1.6 \mathrm{~m}$ for $D_{c}$, and range from 0 to $0.028 \mathrm{~m}^{-1}$ for $\mu^{\prime}(0)$. This has to be compared with the result of section 4.1: the domain $\mathcal{D}$ was from 0.8 to $1.5 \mathrm{~m}$ for $D_{c}$, and from 0 to 0.028 $\mathrm{m}^{-1}$ for $\mu^{\prime}(0)$. The static stress slightly extends the domain $\mathcal{D}$ towards greater $D_{c}$, for which the dynamic pulse was not efficient enough to trigger the event.

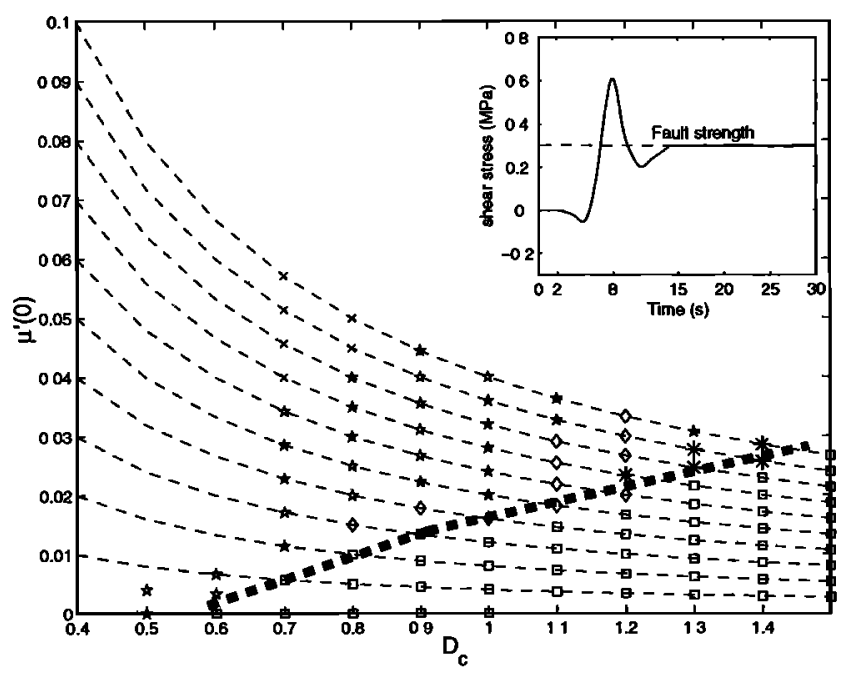

Figure 11. Same legend as in Figure 8. We use the complete CFF computed by Belardinelli et al. [1999]. The fault strength is greater than the static stress field. The thick dashed line shows the domain $\mathcal{D}$ that extends from $0.2 \mathrm{~m}$ to $1 \mathrm{~m}$ for $D_{c}$, with $\mu^{\prime}(0)$ lower than 0.04 $\mathrm{m}^{-1}$.

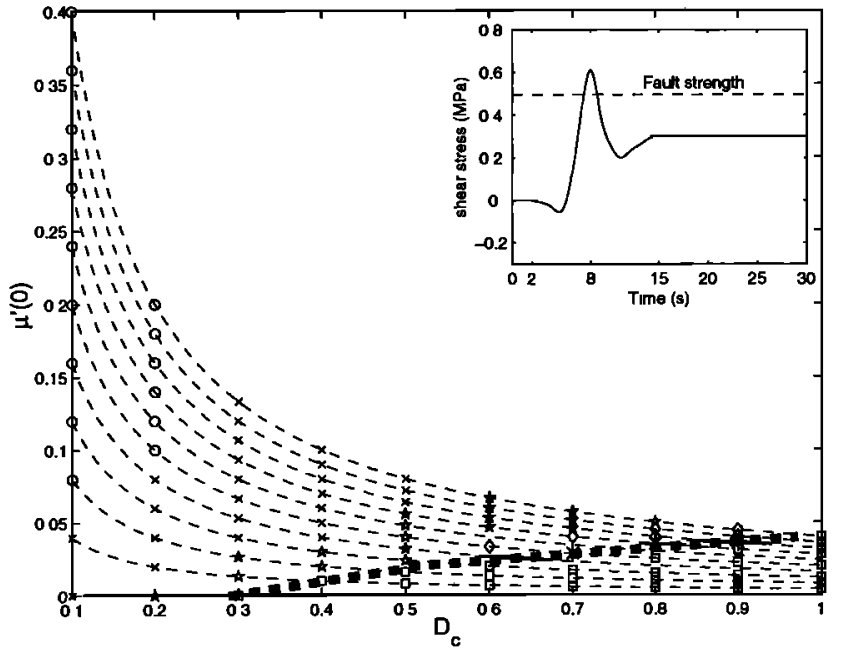

Figure 12. Same legend as in Figure 8. We use the complete CFF computed by Belardznell et al. [1999]. The fault strength is greater than the initial state of stress. 'The thick dashed line shows the domain $\mathcal{D}$ that extends from $0.5 \mathrm{~m}$ to $1.5 \mathrm{~m}$ for $D_{c}$, with $\mu^{\prime}(0)$ lower than $0.038 \mathrm{~m}^{-1}$.

\subsection{Computations for a Far From Failure Fault}

In this section, the fault strength is equal to the static stress field provided by the first event. The results of our computations are shown in Figure 11. The main difference between Figures 10 and 11 is the position of the threshold. From $0.8 \mathrm{~m}$, it has fallen down to 0.6 m. The relative positions of the fault strength and of the initial stress control the value of this threshold: it is around $0.8 \mathrm{~m}$ for a close to failure fault, and around $0.6 \mathrm{~m}$ for a far from failure fault. The domain $\mathcal{D}$ now extends from 0.6 to $1.4 \mathrm{~m}$ for $D_{c}$ and from 0 to 0.038 $\mathrm{m}^{-1}$ for $\mu^{\prime}$. This has to be compared with the results of section 4.2 ; the domain $\mathcal{D}$ was from 0.5 to $1.2 \mathrm{~m}$ for $D_{c}$ and less than $0.028 \mathrm{~m}^{-1}$ for $\mu^{\prime}(0)$. Once again we see that the static stress field extends the domain $\mathcal{D}$ toward greater $D_{c}$ values.

\subsection{Computations for a Very Far From Failure Fault}

We have shown that the difference $R$ between $\sigma$ the shear strength and the initial stress level $\tau_{0}$ governs the exıstence and the position of a threshold for the critical slip on fault. In the previous paragraphs the shear strength was equal to the initial stress level $(R=0$ $\mathrm{MPa})$ or to the static stress level $(R=0.3 \mathrm{MPa})$. Here we present two other cases for which the shear strength is higher than the static stress level. Figures 12 and 13 show the results of the computations for $R=0.5 \mathrm{MPa}$ and $R=0.6 \mathrm{MPa}$ (close to the maximum of the stress pulse) respectively. The only difference is the threshold position. In the case $R=0.5 \mathrm{MPa}$, the threshold is around $0.2-0.3 \mathrm{~m}$. In the case $R=0.6 \mathrm{MPa}$, this threshold falls down to only $0.03 \mathrm{~m}$. Figure 14 represents the evolution of the lowest possible value for $D_{c}$ 


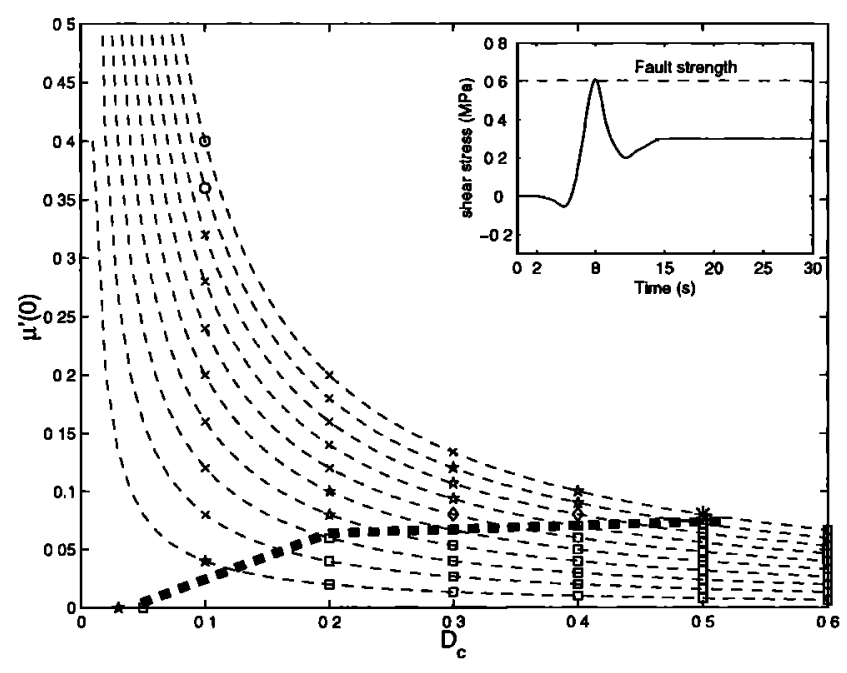

Figure 13. Same legend as in Figure 8. We use the complete CFF computed by Belardinell et al. [1999]. The fault strength is greater than the initial state of stress, close to the dynamic stress peak. The strong dashed line shows the domain $\mathcal{D}$ that extends from 0.03 $\mathrm{m}$ to $0.6 \mathrm{~m}$ for $D_{c}$, with $\mu^{\prime}(0)$ lower than $0.05 \mathrm{~m}^{-1}$.

(the threshold value) with $R$, the difference between the initial stress and the fault strength. This figure summarizes all our results and permits us to constrain a domam $\left(R, D_{c}\right)$ that complies with the observed clelay. Our simulations suggest that when a fault is far from failure the triggering threshold is independent of $D_{c}$ (for values between $0.03 \mathrm{~m}$ and $0.8 \mathrm{~m}$ ). It is worth noting that the lowest possible value for $D_{c}$ is only a function of the relative values of the shear strength and of the initial state of stress. The static stress field is of no importance for this threshold and this explains why we have the same threshold for a "close to failure" fault with or without the static stress field $(0.8 \mathrm{~m})$. The upper limit to the triggering threshold is provided by the maximum of the dynamic stress peak, which has to be greater than the fault strength. The upper $D_{c}$ limit that separates the triggering and the nontriggering domain is given by the maximum value of $D_{c}$ that leads to the observed delay. The lower limit is given by the theoretical work by Burradge [1973]. He has demonstrated, for the plane-strain self-similar shear crack, that the rupture front velocity is a function of the relative values of $\tau_{0}, \sigma$, and $\tau_{d}$ : the parameter

$$
S=\frac{\sigma-\tau_{0}}{\tau_{0}-\sigma_{d}}
$$

controls the rupture front velocity. Following Belardinell et al. [1999], the rupture front velocity is about $2.8 \mathrm{~km} / \mathrm{s}$ on the second fault segment, close to the Rayleigh velocity. This implies according to Burridge [1973], that $S>1.63$ and therefore:

$$
R \geq 1.63\left(\mu_{s}-\mu_{d}\right)
$$

This lower limit is plotted on Figure 14. Figure 14 provides a correlation between the strength of the fault and the lowest admissible value for the critical slip. If the fault is close to failure, $D_{c}$ may range from 0.8 to $1.5 \mathrm{~m}$. If the fault is far from failure, it allows smaller values for $D_{c}$. In the extreme case $D_{c}$ may decrease to only $0.03 \mathrm{~m}$. Inversely, small critical slip $D_{c}$ values imply a high strength of the fault.

\section{Discussion}

The thurd question we asked was: Does the timing of the Irpinia sequence constrain the friction law parameters? Our numerical simulations indicate that the critical slip $D_{c}$ may range from $0.03 \mathrm{~m}$ to $1.7 \mathrm{~m}$. This range has to be compared with other studies. Ohnaka [1996] performed a series of laboratory experiments on block of granite of $30 \mathrm{~cm}$ in length. He measured a critical slip $D_{c}$ of the order of 1-2 $\mu \mathrm{m}$. From the seismological records, Matsu'ura et al. [1992] have estimated the width of the initiation zone (so-called $l_{c}$ ) for major earthquakes $(M=7.0-7.7)$ to $5-10 \mathrm{~km}$, which leads to a characteristic length $D_{c}$ of the order of $1 \mathrm{~m}$. In the same way, Ito [1992] and Ellsworth and Beroza [1995, 1998] have compiled a series of earthquakes with magnitudes 2.0-8.0: they infer an initiation phase and they propose a critical slip $D_{c}$ ranging from $1 \mathrm{~mm}$ to $1 \mathrm{~m}$. These authors propose that the critical slip and the initiation duration both scale with the magnitude of the associated event, such that a duration of $10 \mathrm{~s}$ would correspond to a $\mathrm{M}=8$ earthquake. The total moment magnitude of the Irpinia sequence is 6.9 , and the second

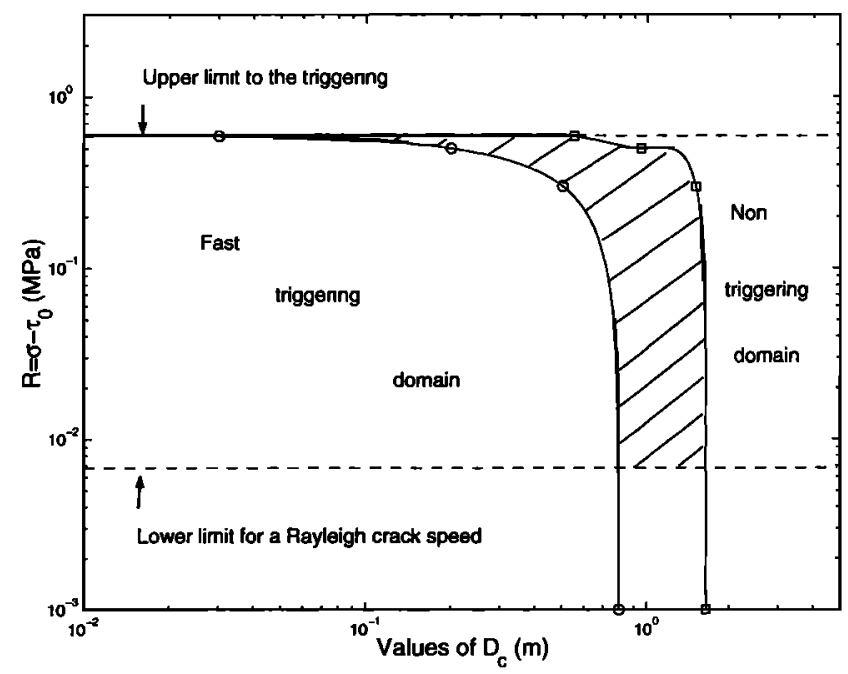

Figure 14. Evolution of the lowest (circles) and largest (scuares) possible $D_{c}$ values with $R$, the difference betwcen the fault strength and the initial stress level $\sigma-\tau_{0}$. 'The upper limit for the triggering is determined by the maximum amplitude of the dynamic stress peak that has to be greater than the fault strength. The right lateral limit between the triggering and the nontriggering domain is given by the greater value of $D_{c}$ that matches the observed delay. The lower limit is derived from the theoretical work by Burridge [1973]. The hatched area is the domain of the admissible values for $D_{c}$. 
subevent is much smaller. This contradiction caused Brlardmelle et al. [1909] to interpret the $10 \mathrm{~s}$ time delay (between the dynamic stress peak and the onset of the rupture on the second fault segment) in terms of rate-and-state-dependent friction law. However, their analysis did not take into account the finite fault effect on the initiation duration. Ionescu and Campillo [1999] show that the fault finiteness is of great influence on the initiation duration when the length of the fault is of the order of the width of the initiation zone prescribed by $D_{r}$ or $\mu^{\prime}(0)$. Since the length of the fault is fixed in our geometry to $10 \mathrm{~km}$, we propose to explain this time clelay with a smple slip dependent friction law and to consider not only $D_{\approx}$ but also $\mu^{\prime}$ as a main control parameter of the initiation phase. The permissible values of $D_{c}$ range from $0.03 \mathrm{~m}$ to $1.7 \mathrm{~m}$, and are always less than $0.04 \mathrm{~m}^{-1}$ for $\mu^{\prime}(0)$. Our simulations are consistent with the seismological estimations of the critical slip $D_{c}$ rather than with the laboratory measures. These values have been found considering a stress drop of $8.3 \mathrm{MPa}$, a static friction coefficient $\mu_{s}=0.6$, a dynamic friction coefficient $\mu_{d}=056$ These limits to the threshold in the critical slip are likely to change with the choice of the model parameters. Moreover, these numerical results may be consistent only for the case of Irpinia.

The second question we asked was: Is it possible to constrain the fault strength? Unfortunately, our numerical simulations are unable to discriminate between a close to failure fault and a far from failure fault, since both of them may explain a time delay of $20 \mathrm{~s}$. Despite the fact that the absolute magnitude of the fault sirength is still unknown, we have showed that the relative magnitude of the fault strength to the initial stress one governs the existence and the value of a lower $D_{c}$ threshold. We have derived a general relation between the fault strength and the critical slip $D_{c}$ : a close to failure fault implies a critical slip $D_{c} \geq 0.8 \mathrm{~m}$, and a small critical slip $D_{c} \approx 0.03 \mathrm{~m}$ implies a far from failure fault in order to match to the triggering delay observed in the Irpinia sequence. The existence of a threshold for the critical slip provides a relation between admissible critical slip values and the fault strength relative to the initial stress. It takes on $0.4-0.5 \mathrm{~m}$ for a far from failure fault segment, and $0.7-0.8 \mathrm{~m}$ for a close to failure fault segment The very far from failure fault, for which the fault strength is higher than the static stress field value leads to a even smaller $D_{c}$ threshold: it takes on $0.2 \mathrm{~m}$ for the intermediate case ( $R=0.5 \mathrm{MPa})$ and $0.03 \mathrm{~m}$ for the extreme case. Once again, the numerical value of this threshold may be sensitive to the choice of the parameters of our model. However, the existence of this threshold is independent from the values of the parameters.

The first question we asked was: Is it possible to discriminate between the dynamic and the static effects on the triggering of the second subevent, if these effects exist? Our simulations provide a good argument in favor of the dynamic aspect of the triggering that could help to understand these two points. Our work shows that an event can be triggered by a transient stress perturbation where positive values of the CFF alternates with negative values during the wave arrivals on the fault of the triggered event. We show that this triggering can ocrur even if the final static stress perturbation is equal to zero. We also show that in the case of triggering by a transient pulse, the initiation duration can be much longer than the pulse duration. Even if we have concentrated on friction law parameters that provide long intiation duration, in a lot of cases the fault ruptured before the static stress was reached. The static stress field simply extends the domain $\mathcal{D}$ toward greater $D_{c}$. That is, in a lot of cases, the dynamic stress pulse is sufficient to trigger the event. King et al. [1994] describes the static stress changes after a series of mainshocks in California, culminating in the Landers, California, earthquake. They show the existence of a correlation between areas in which the static stress is increased, and many aftershocks (the stress trigger zones), and also between areas in which the static stress is decreased and few aftershocks (the stress shadow zones). Despite the first correlation, the existence of some aftershocks in the stress shadow zones is not easy to explain. The decrease in stress unloads the fault region and should delay the next event in the concerned area. Our simulations provide a possible explanation for these aftershocks. In the stress shadow the difference between the fault strength and the static stress increases, that is, the faults become farther from failure. However, we saw previously that the dynamic and transient stress pulse may trigger events on such faults. The Irpinia sequence has been studied because of the relatively short time delay between the two first events: $20 \mathrm{~s}$. We have shown that for such a short delay, the dynamic stress field is more important than the static stress field. Could other events associated with longer duration be explained in the same way? Kilb et al. [1999] have considered the Landers, California, aftershocks map. They consider not only the static stress field but the complete $\triangle C F S(t)$, that is, they account for the dynamic phase. They have shown that the peak of the $\triangle C F S^{\prime}(t)$ (the dynamic stress peak) better correlates with the map of seismicity rate change, positive or negative than the static stress field do. This would imply that the dynamic stresses exert a controlling influence on the aftershock triggering, even for long (months to years) time delays. Since the dynamic stress pulse may trigger an event, even in regions where the $\triangle C F S<0$, it is probable that the same dynamic stress pulse is able to trigger an event in regions where $\triangle C F S \approx 0$. That is to say the dynamic stress pulse is a possible explanation for long-distance triggering.

\section{Conclusion}

By considering the time evolution of a dynamic instability, we have shown that the delay before the triggering, that is, the duration of the initiation phase, depends on the friction parameters. We have shown, as- 
suming a stress drop of $8.3 \mathrm{MPa}$, that the initial slope of the friction has to be lower than $0.04 \mathrm{~m}^{-1}$, whereas $D_{c}$ ranges from $0.03 \mathrm{~m}$ up to $1.7 \mathrm{~m}$. Thus we propose $\mu^{\prime}(0)$ is a primary controlling parameter in the friction law when invoked to explain delayed rupture, as suggested by Ionescu and Campillo [1999]. Our simulations show the existence of a lower threshold in $D_{c}$ under which the fault always ruptures before $13 \mathrm{~s}$. The value of this threshold seems to be a function of the relative magnitudes of the fault strength and the initial stress. A close to failure fault is not consistent with a critical slip lower than $0.8 \mathrm{~m}$, and small critical slip values $(0.03 \mathrm{~m})$ are consistent with a far from failure fault to explain such an observed delay of $20 \mathrm{~s}$ between the first and second rupture. Our study shows that it is possible to trigger an event with dynamic variations of the shear stress and to explain long initiation duration without the effect of the static stress field. This suggests that the triggering of events can occur even in areas where the static stress is decreased, since it can be due only to dynamic variations of stress. This result provides a possible explanation for long-distance triggering by propagating waves.

Acknowledgments. This work benefited from the comments of R. Harris, M. Cocco, and J. Gomberg. This first paper is dedicated to the first author's family.

\section{References}

Aki, K., and P.G. Richards, Quantitative Seismology, vol. II, 932 pp., W.H. Freeman, New York, 1980.

Anderson, J.G., J.N. Brune, J.N. Louie, Y. Zeng, M. Savage, G. Yu, Q. Chen, and D. dePolo, Seismicity in the western Great Basin apparently triggered by the Landers, California, earthquake, 28 June 1992, Bull. Seismol. Soc. Am., 84, 863-891, 1994.

Bak, P., and C. Tang, Earthquakes as a self-organized critical phenomenon, J. Geophys. Res., 94, 15,635-15,637, 1989.

Belardinelli, M.E., M. Cocco, O. Coutant, and F. Cotton, The redistribution of dynamic stress during coseismic ruptures: Evidence for fault interaction and earthquake triggering, J. Geophys. Res., 104, 14,925-14,945, 1999.

Bodin, P., and J. Gomberg, Triggered seismicity and deformation between the Landers, California, and Little Skull Mountain, Nevada, earthquakes, Bull. Sersmol. Soc. Am., 84, 835-843, 1994.

Burridge, R., Admissible speeds for plane-strain self-similar shear cracks with friction but lacking cohesion, Geophys. J. R. Astron. Soc., 35, 439-455, 1973.

Byerlee, J.D., Friction of rock, Pure Appl. Geophys., 116, 615-626, 1978.

Campillo, M., and I. Ionescu, Initiation of antiplane shear instability under slip-dependent friction, J. Geophys. Res., 102, 20,363-20,371, 1997.

Cocco, M., and F. Pacor, Space time evolution of the rupture process from the inversion of strong motion waveforms, Tectonophysics, 218, 157-177, 1993.

Cotton, F., and O. Coutant, Dynamic stress variations due to shear faults in a plane layered medium, Geophys. J. Int., 128, 676-688, 1997.

Das, S., and C. Scholz, Off-fault aftershock clusters caused by shear stress increase?, Bull. Seismol. Soc. Am., 71, 1669-1675, 1981.
Dascalu C., I.R. Ionescu, and M. Campillo, Fault finiteness and initiation of dynamic shear instability, Earth Planet. Scz. Lett., 177, 163-176, 2000.

Deng, J., and L.R. Sykes, Triggering of the 1812 Santa Barbara earthquake by a great San Andreas shock: Implications for future seismic hazards in southern California, (ieophys. Res. Lett., 23, 1155-1158, 1996.

Dieterich. J.H.. Modeling of rock friction, 1, Experimental results and constitutive equations, J. Geophys. Res., 84, 2161-2175, 1979.

Ellsworth. W.L., and G.C. Beroza, Seismic evidence for an earthquake nucleation phase, Science, 268, 851-854, 1995.

Ellsworth, W.L., and G.C. Beroza, Observation of the seismic nucleation phase in the Ridgecrest, California, earthquake sequence, Geophys. Res. Lett., 25, 401-404, 1998.

Gomberg, J., and P. Bodin, Triggering of the $M_{s}=5.4$ Little Skull mountain, Nevada, earthquake with dynamic strain, Bull. Sevsmol. Soc. Am., 84, 844-853, 1994.

Gomberg, J., and S. Davis, Stress/strain changes and triggered seismicity at the Geysers, California, J. Geophys. Res., 101, 733-749, 1996.

Gomberg, J., M.L. Blanpied, and N.M. Beeler, Transient triggering of near and distant earthquakes, Bull. Seismol. Soc. Ain., 87, 294-309, 1997.

Gomberg, J., N.M. Beeler, M.L. Blanpied, and P. Bodin, Earthqualie triggering by transient and static deformalions, J. Geophys. Res., 103, 24,411-24,426, 1998.

Grasso, J.R. and D. Sornette, Testing self organized criticalily by induced seismicity, J. Geophys. Res., 103, 29,965$29,988,1998$.

Harclebeck, J.L., J.J. Nazareth, and E. Haucksson, The static stress change triggering model: Constraints from two southern California aftershocks sequences, J. Geophys. Res., 10.3, 24,427-24,438, 1998.

Harris, R.A.. Stress triggers, stress shadows, and implicalions for seismic hazard, J. Geophys. Res., 103, 24,34724,358, 1998.

Harris, R.A., and S.M. Day, Dynamics of fault interaction: Parallel strike-slip faults, J. Geophys. Res., 98, 4461-4472, 1993.

Harris, R.A., and R.W. Simpson, Changes in static stress on southern ('alifornia faults after the 1992 Landers earthquake, Nalure, 360, 251-254, 1992.

Harris, R.A., and R.W. Simpson, ln the shadow of 1857 : 'The effect of the great. Ft. Tejon earthquake on subsequent earthquakes in southern California, Geophys. Res. Lett., 2.3, $229-232,1996$.

Harris, R.A., and R.W. Simpson, Suppression of large earth(quakes by stıcss shadows: A comparison of Coulomb and rate and stat. failure, J. Geophys. Res., 103, 24,439$24,452,1998$.

Harris, R.A., R.W. Simpson, and P.A. Reasenberg, Influence of static stress changes on earthquakes location in southern ('alifornia, Nature, 375, 221-224, 1995.

Hill, D.P., P A. Reasenberg, A. Michael, W.J. Arabaz, and (i.c: Beroza , Selsmicity remotely triggered by the magnitude 7.3 Landers, California, earthquake, Science, 260, $1617-1623,1993$.

Iio, Y., Slow initial phase of the $P$ wave velocity pulse generated by microearthquakes, Geophys. Res. Lett., 19, 477 $180,1992$.

Iio. Y., Frictional coefficients on faults in a seismogenic region inferred from earthquake mechanism solutions, $J$. Geophys. Res., 102, 5403-5412, 1997.

Ionescu, I.R. and M. Campillo, The influence of the shape of the friction law and fault finiteness on the duration of initiation, J. Geophys. Res., 104, 3013-3024, 1999.

Jaumé, S.C., and L.R. Sykes, Change in the state of stress on 
the southern San Andreas fault resulting from the Califor1ua earthquakes sequence of April to June 1992, Science, $258,1325-1328,1992$.

Jaumé, S $($., and L.R. Sykes, Evolution of moderate seismicity in the San Fransisco Bay region, 1850 to 1993: Seismicity changes related to the occurrence of large and great earthruakes, J. Geophys. Res., 101, 765-789, 1996.

Kilb, D., J. Ciomberg, and P. Bodin, Complete coulomb failure stress changes and earthquake triggering, (abstract), Eos Trans. AGU, 80(46), Fall Meet. Suppl., F1005-F1006, 1999

King, G.C.P., R.S. Stein, and J. Lin, Static stress changes and the triggering of earthquakes, Bull. Seismol. Soc. Am., 84, 935-953, 1994.

Matsu'ura, M., H. Kataoka, and B. Shibazaki, Slipclependent friction law and nucleation processes in earthcuake rupture, Tectonophysics, 211, 135-148, 1992.

Nalbant, S.S., A. Hubert, and G.C.P. King, Stress coupling between earthquakes in northwest Turkey and the north Aegean Sea, J. Geophys. Res., 103, 24,469-24,486, 1998.

Nostro, C.. M. Cocco, and M.E. Belardinelli, Static stress changes in extensional regimes: An application to southern Appeninnes (Italy), Bull. Seismol. Soc. Am., 87, 234248, 1997 .

Ohnaka, M. Nonuniformity of the constitutive law parameters for shear rupture and quasistatic nucleation to dynamic rupture: A physical model of earthquake generation processes, Proc. Natl. Acad. Sci. U. S. A., 93, 37953802, 1996.

Okada, Y., and K. Kasahara, Earthquake of 1987, off Chiba, central Japan and possible triggering of eastern Tokyo earthquake of 1988, Tectonophysics, 172, 351-364, 1990.

Pantosti, D., D.P. Schwartz, and G. Valensise, Paleosismology along the 1980 Irpinia earthquake fault and implications for earthquake recurrence in the southern Apennines, J. Geophys. Res., 98, 6561-6577, 1993.

Pingue, F., G. De Natale, and P. Briole, Modeling of the 1980 Irpinia earthquake source: Constraints from geodetic data, Ann. Geofis., 36, 27-40, 1993.

Reasenberg, P.A., and R.W. Simpson, Response of regional seismicity to the static stress change produced by the Loma Prieta earthquake, Science, 255, 1687-1690, 1992.

Ruina, A.L., Slip instability and state variable friction laws. J. Geophys. Res., 88, 10,359-10,370, 1983.

Rybicki, K., Analysis of aftershocks on the basis of dislocation theory, Phys. Earth Planet. Inter., 7, 409-422, 1973.
Scholz C.H., The Mechanics of Earthquakes and Faulting, 139 pp., Cambridge Univ. Press, New York, 1990.

Simpson, R.W., S.S. Schulz, L.D. Dietz, and R.O. Burford, 'The response of creeping parts of the San Andreas fault to earthquakes on nearby faults: Two examples, Pure Appl. ('cophys., 1:6, 665-685, 1988.

Smith, S.W. and W. Van de Lindt, Strain adjustments associated with earthquakes in southern California, Bull. Sersmol. Soc. 1m. 59, 1569-1589, 1969.

Stem, R.S., and M. Lisowski, The 1979 Homestead Valley (arthquake sequence, California: Control of aftershocks and postseismic deformation, J. Geophys. Res., 88, 64776490, 1983.

St.ein, R.S., G.C.P. King, and J. Lin, Change in failure stress on the southern San Andreas fault system caused by the 1992 magnitude $=7.4$ Landers earthquake, Science, 258 , 1328-1332, 1992.

Stein, R.S., G.C.P. King, and J. Lin, Stress triggering of the $M=6.7$ Northridge, California, earthquake by its predecessors, Science, 265, 1432-1435, 1994.

Toda, S., R.S. Stein, P.A. Reasenberg, J.H. Dieterich, and A. Yoshicla, Stress transferred by the $1995 M_{w}=6.9$ Kobe, Japan, shock: Effect on aftershocks and future earthquake probabilities, J. Geophys. Res., 103. 24,543-24,565, 1998.

Troise, C., G. De Natale, F. Pingue, and S.M. Petrazzuoli, Evidence for static stress interaction among earthquakes in the south-central Apennines (Italy), Geophys. J. Int., 134, 809-817, 1998.

Vaccari, F., P. Harabaglia, P. Suhadolc, and G.F. Panza, The Irpinia (Italy) 1980 earthquake: waveform modeling of accelerometric data and macroseismic considerations, Ann. Geofis., 36, 93-108, 1993.

Zoback, M.D. and J. Healy, Friction, faulting and in-situ stress, Ann. Geophys., 2, 689-698, 1984.

M. Campillo and C. Voisin, Laboratoire de Géophysique Interne, Observatoire de Grenoble, Université Joseph Fourier, BP 53X, 38041 Grenoble Cedex, France. (cvoisin@obs.ujf-grenoble.fr)

F. Cotton and O. Scotti, Institut de Protection et de Sûreté Nucléaire, 92265 Fontenay aux Roses, France.

I. R. Ionescu, Laboratoire de Mathématiques Appliquées, Université de Savoie, 73376 Le Bourget-du-Lac, France.

(Received August 4, 1999; revised March 2, 2000; accepted April 18, 2000.) 